\title{
Dissensual Places
}
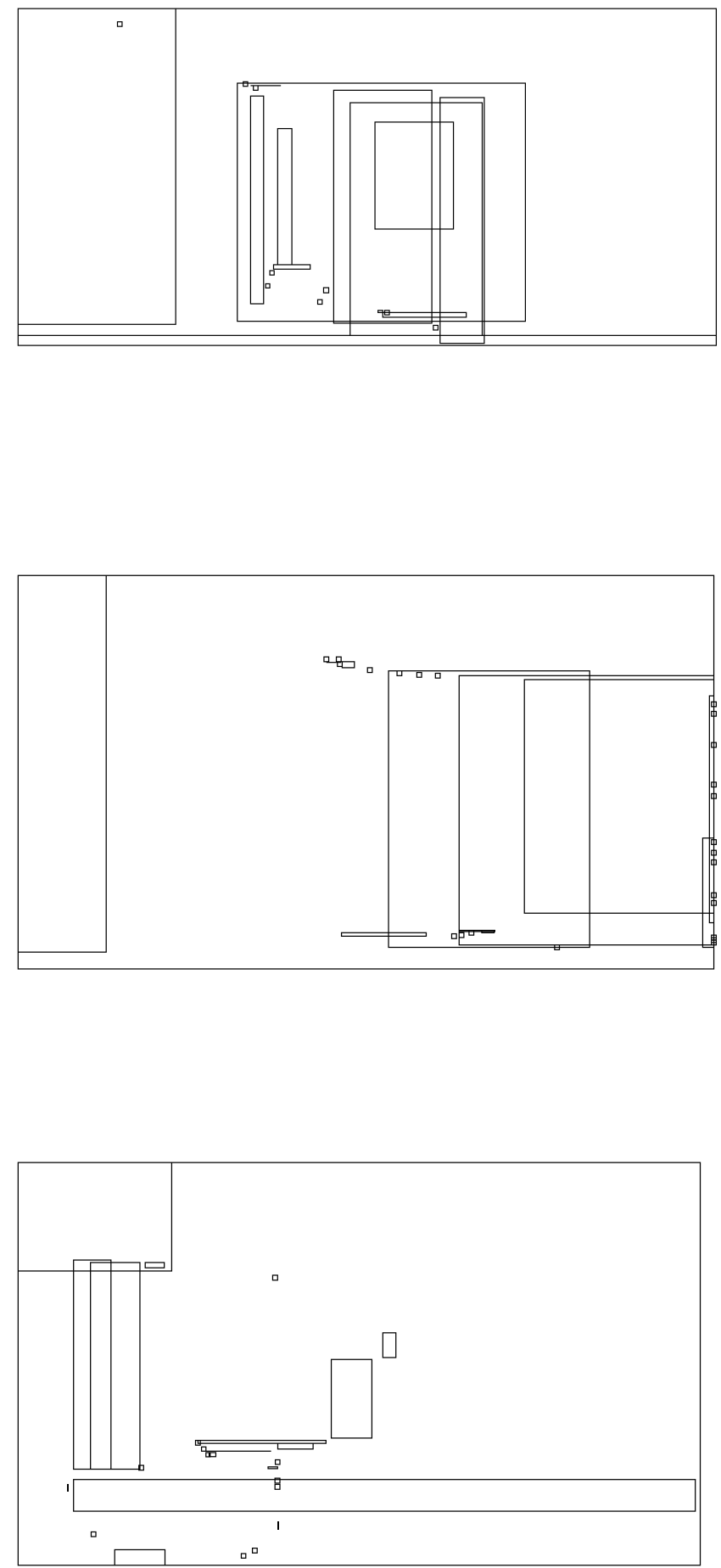

THREE SCENES FROM THE EVERYDAY

OF NETWORKED MEDIA 
Prologue...........................................4

The Actors.........................................6

Dissensual Places............................ 8

Scene I

With 2 Models and 3 Designs.

Scene II

With 3 MOdels AND 3 DEsigns.

Scene III

With 1 MODEL AND 4 DESIGNS

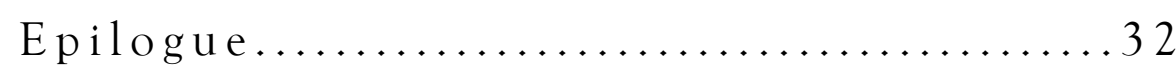

Imprint....................................... 34 
O all the scenes that networked media offer, liking is at once the most exemplary and the most restricted: it is seen as a one-sided action, a passive choice made by one person with reoards to the choice of another. A click or touch aimed at somethingcreated by clickino or touchino.

At least, that is what we are used to, that it is an action consisting of bilateral choices at best. Yet how can that be? As media, networks are built on decision-making, choices that we never oet to see. The reasons for this are many: it would be too much, too confusing, not manageable. But for whom are these good reasons?
In the following scenes of liking, these reasons are ionored. Not because there is nothing to them, but because they are held to not account for how these places work, play and choose. Those words are not precise of course, but that is also the point: none are, while all might.

To be less vague: all scenes actually happened. I liked something. It does not matter what that was, the act was always the same. It is my hope that the diversity of the presented models and desions show how networked places are shared with other decision-makers. Ones that, purely by seeino them, might remake the places. 
User

The most oblivious actor in these scenes, yet one of the most influential. Is capable of influencing an entire scene with little action.

\section{Event}

A sporadic computational appearance, prompting Synthetic and confounding Control.Is not reducible to pre-defined lines.

\section{Contagion}

The lone actor not capable of being designed. Nearly invisible force, yet shaping all scenes in one way or another.

\section{Computation}

The workforce amongst the actors, taking all steps necessary for anything to occur at all. Is exposed to Control and Contagion.

\section{Control}

Constantly attempting to keep everything in balance-meaning what it considers to be the best balance. Has a hard time.

\section{Symthetic}

The actor always seeking to be put into relation with User.

Somewhat tragic, as it never does so without disappearing.

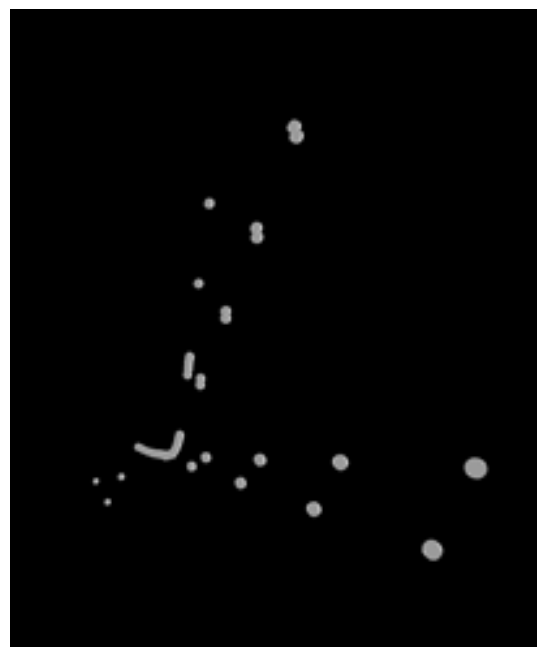

USER, Scene III.]

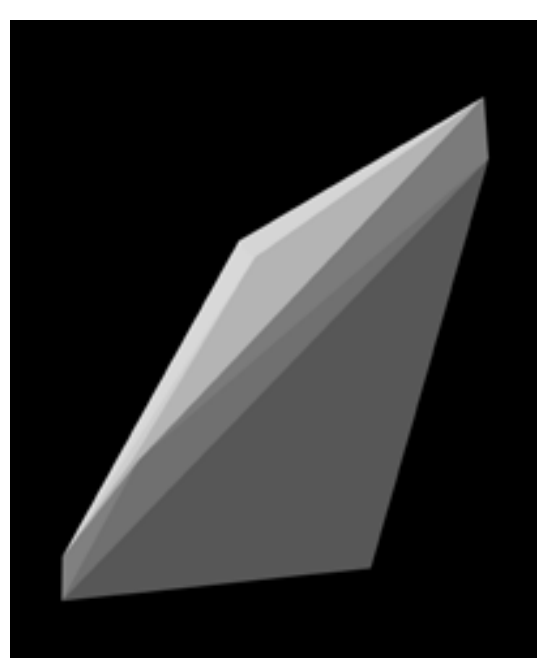

EVENT, Scene III.]

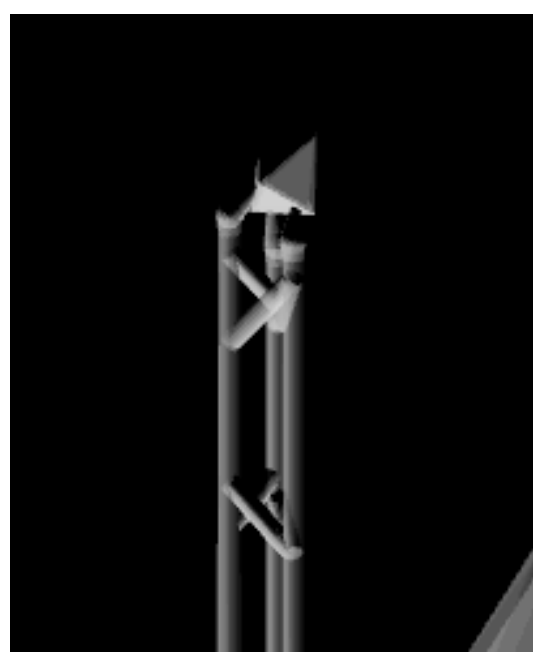

CONTAGION, Scene II.]

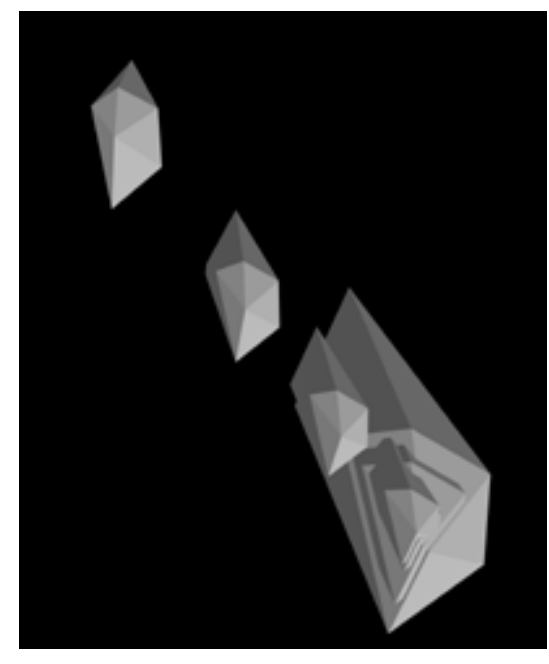

COMPUTATION, Scene II.

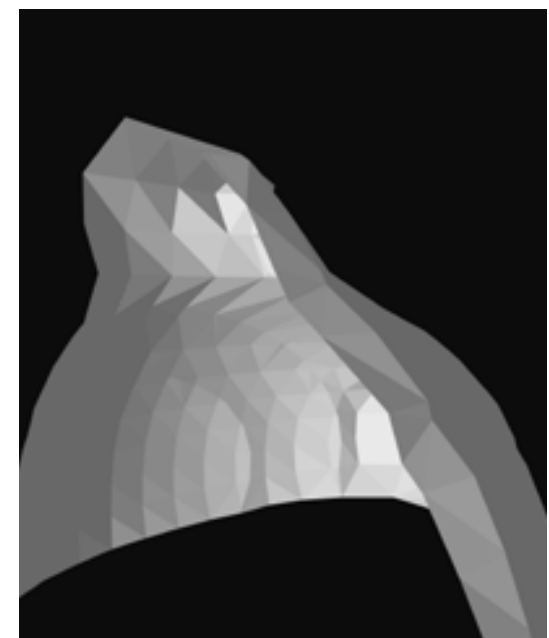

CONTROL, Scene I.]

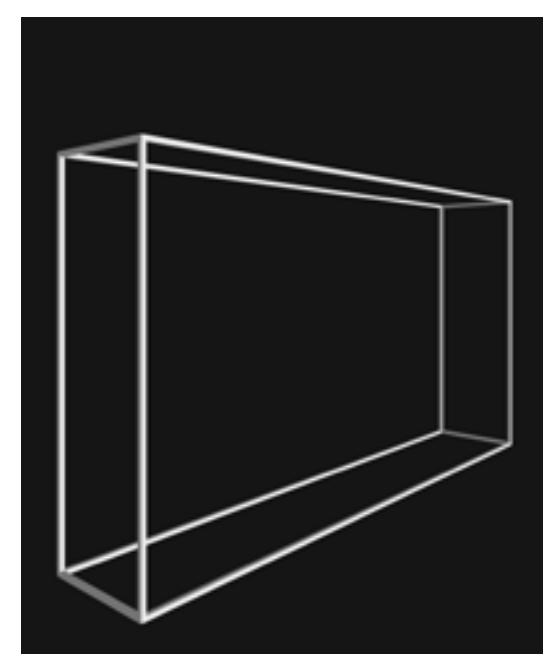

SYNTHETIC, Scene I. 


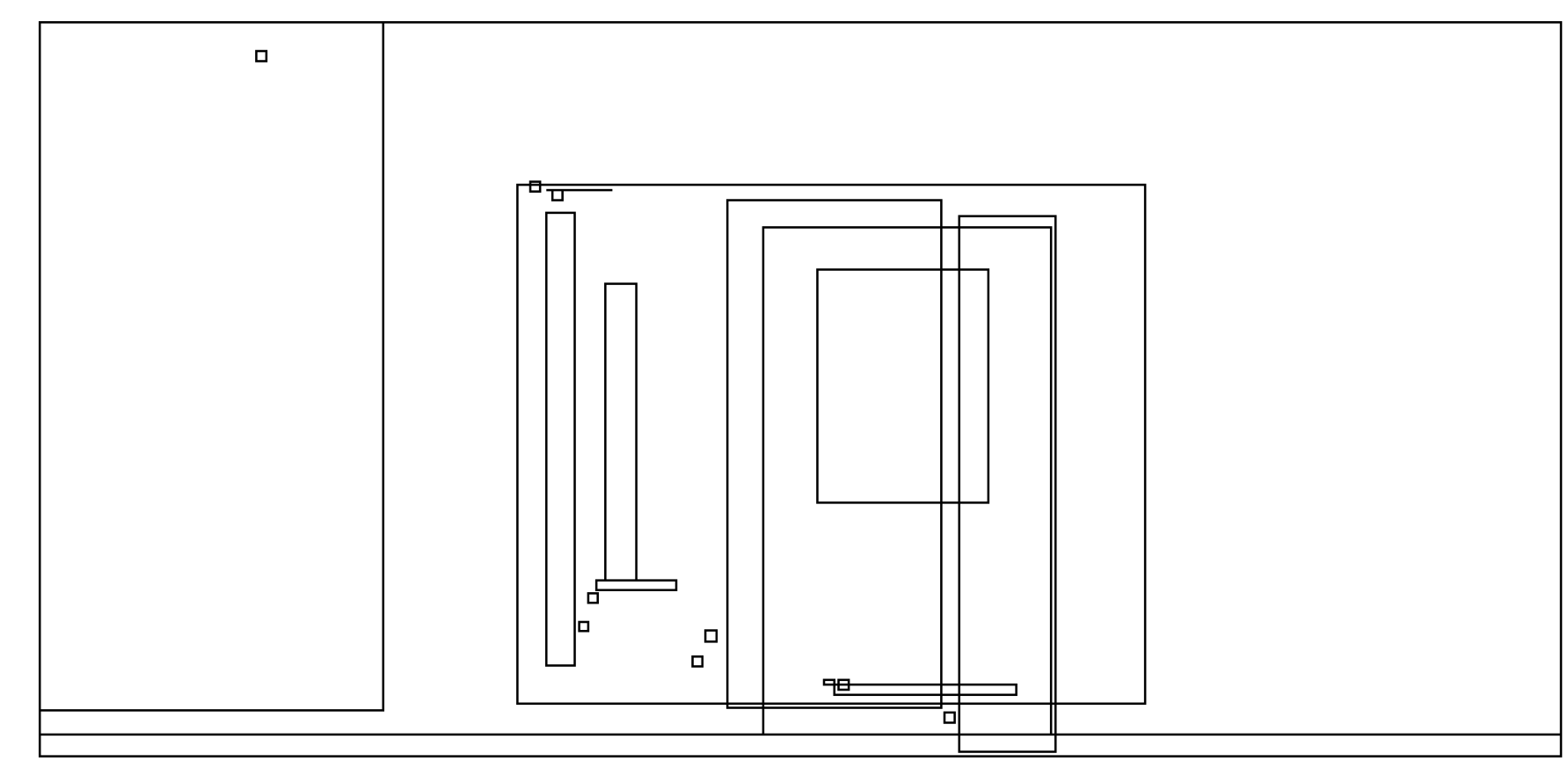

Scene I

Being the liking of a post on

March $15^{\text {th }}$ in a period of inter

action with a networked medic

interface lasting 4.62 seconds.

STAGE (above), COMMON DESIGN (below),

Scene I.]

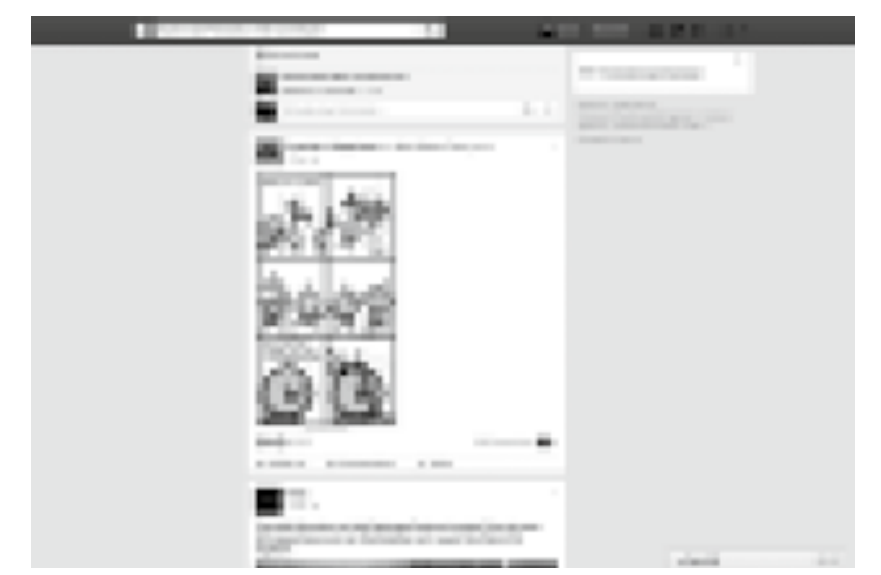


n March $15^{\text {th }}$ I liked a post on a social media platform.

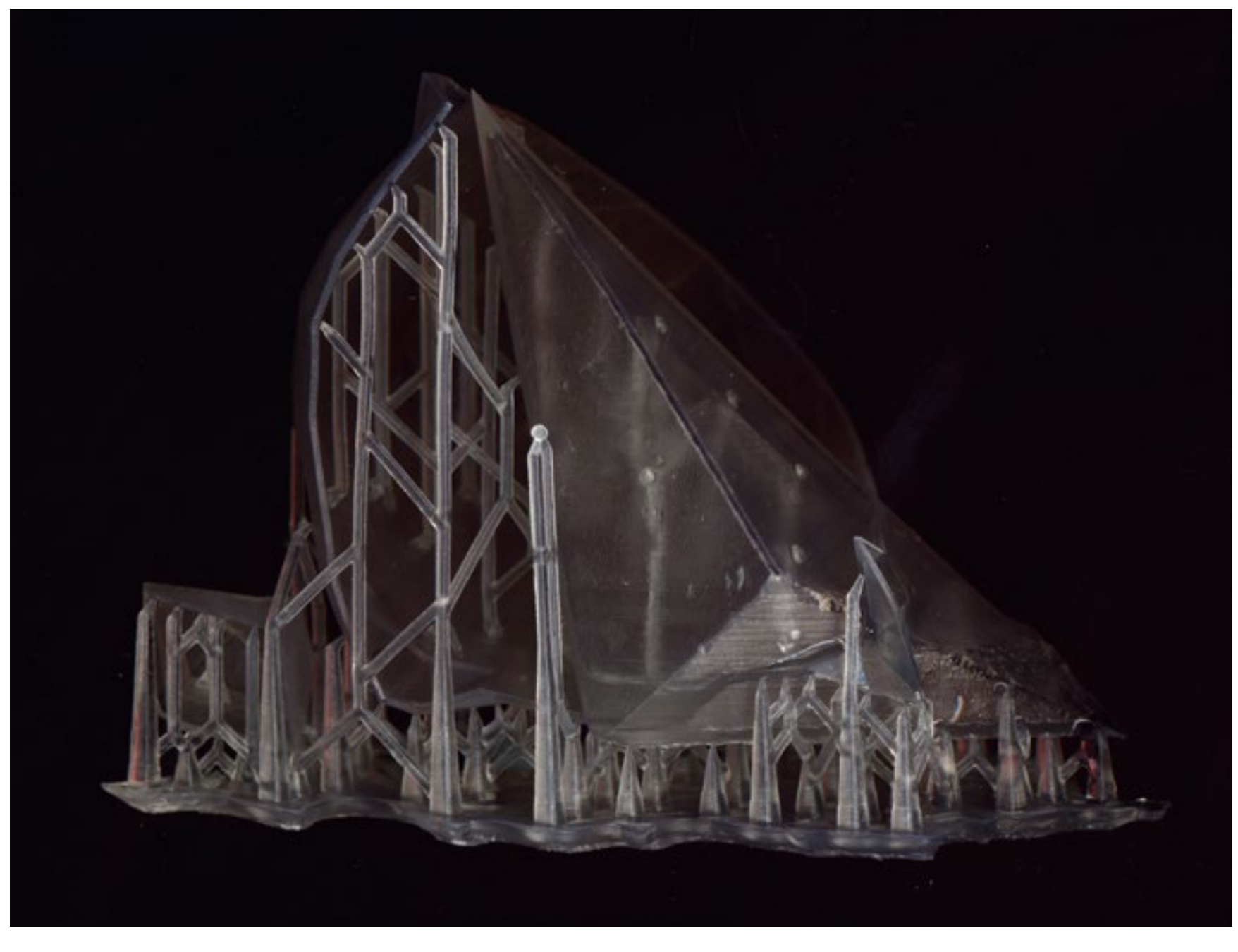

It took me 1.81 seconds to navigate towards it, and click the icon.

10,051 users had already done this before me.

I then tarried, circling my cursor over other options of action, without going ahead with any.

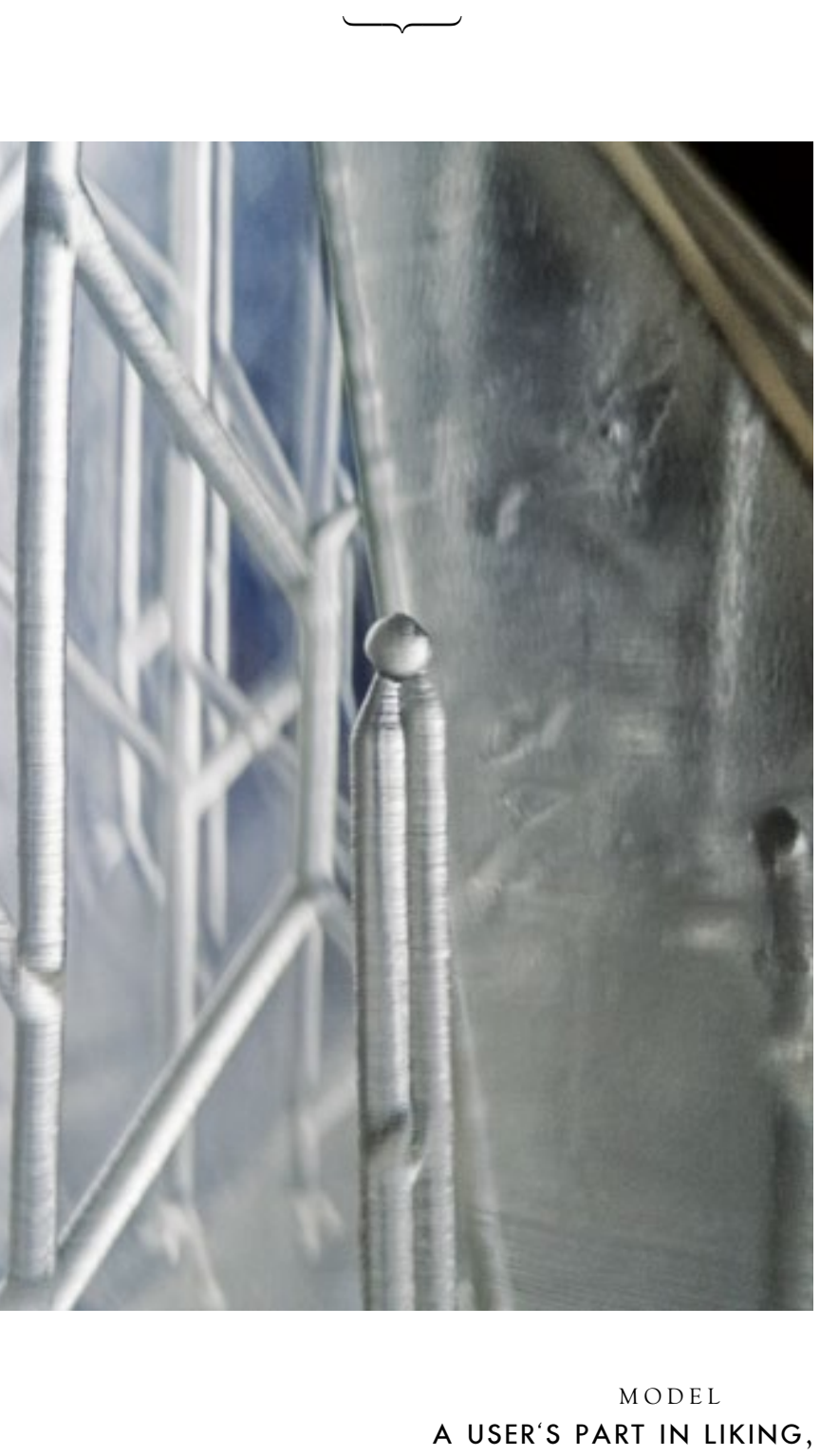




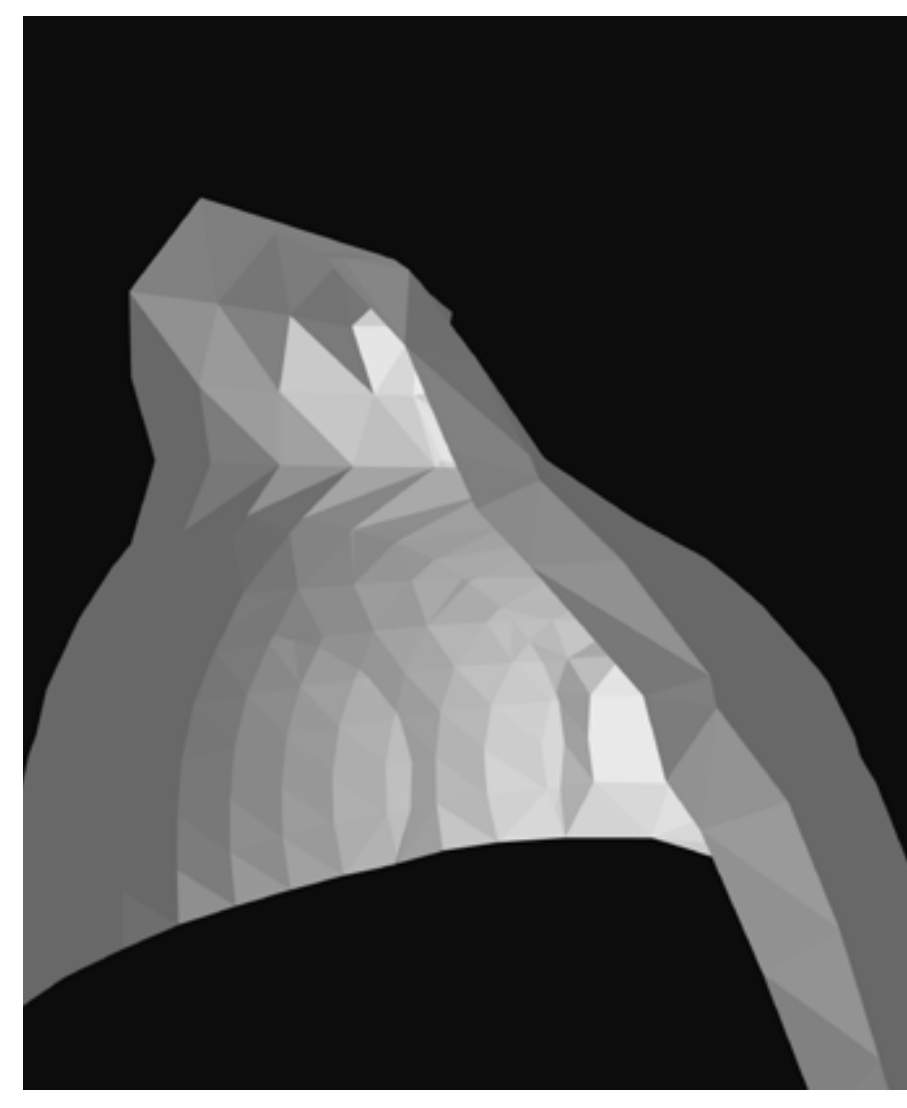

DESIGN CONTROL,
Scene I.

In the period of 4.62 seconds, I had scrolled vertically; therefore my profile, groups and

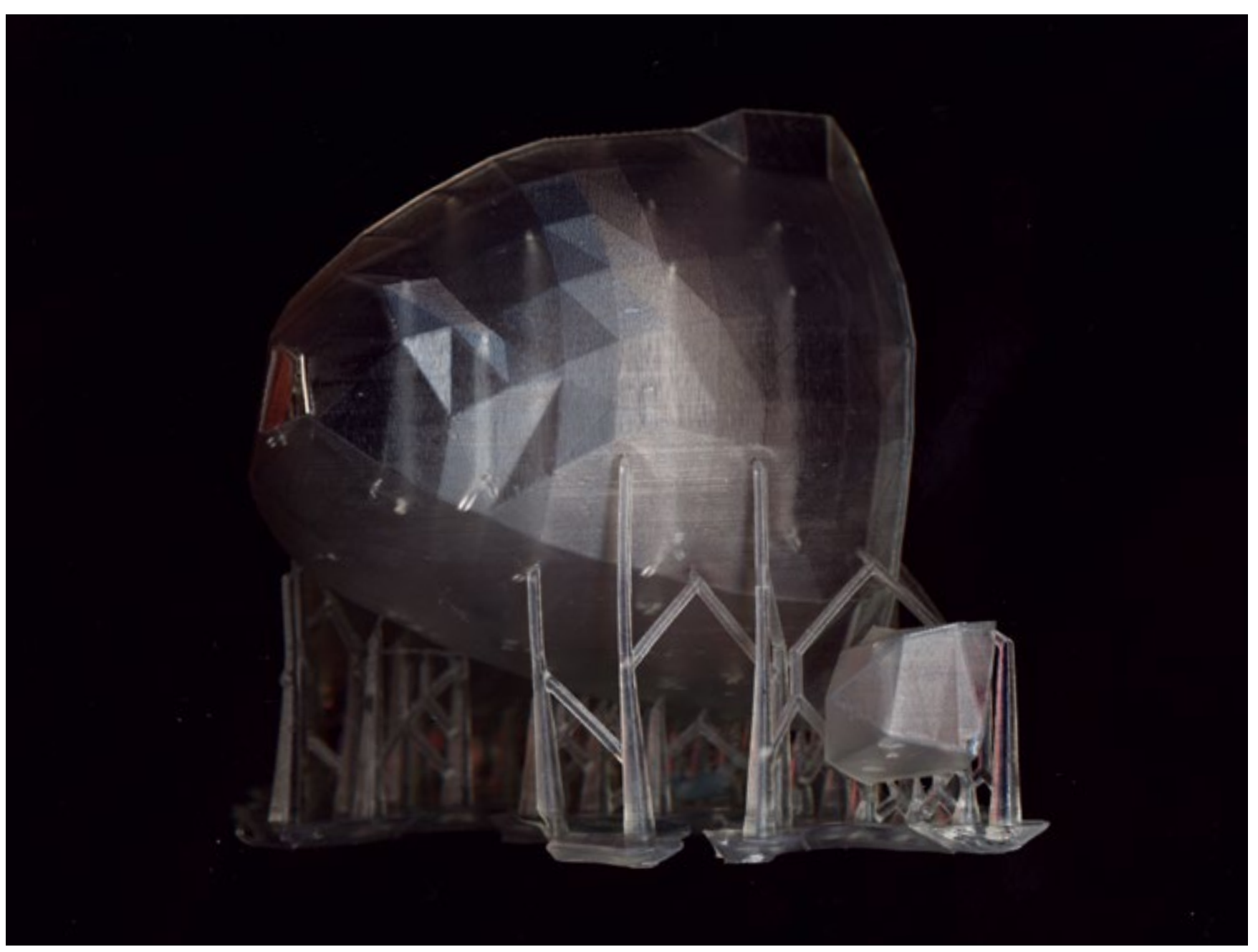

other immediates were temporarily out of re-

[Instead, the left of the screen was empty except for the mellow blue-ish grey of the background-colour.] 


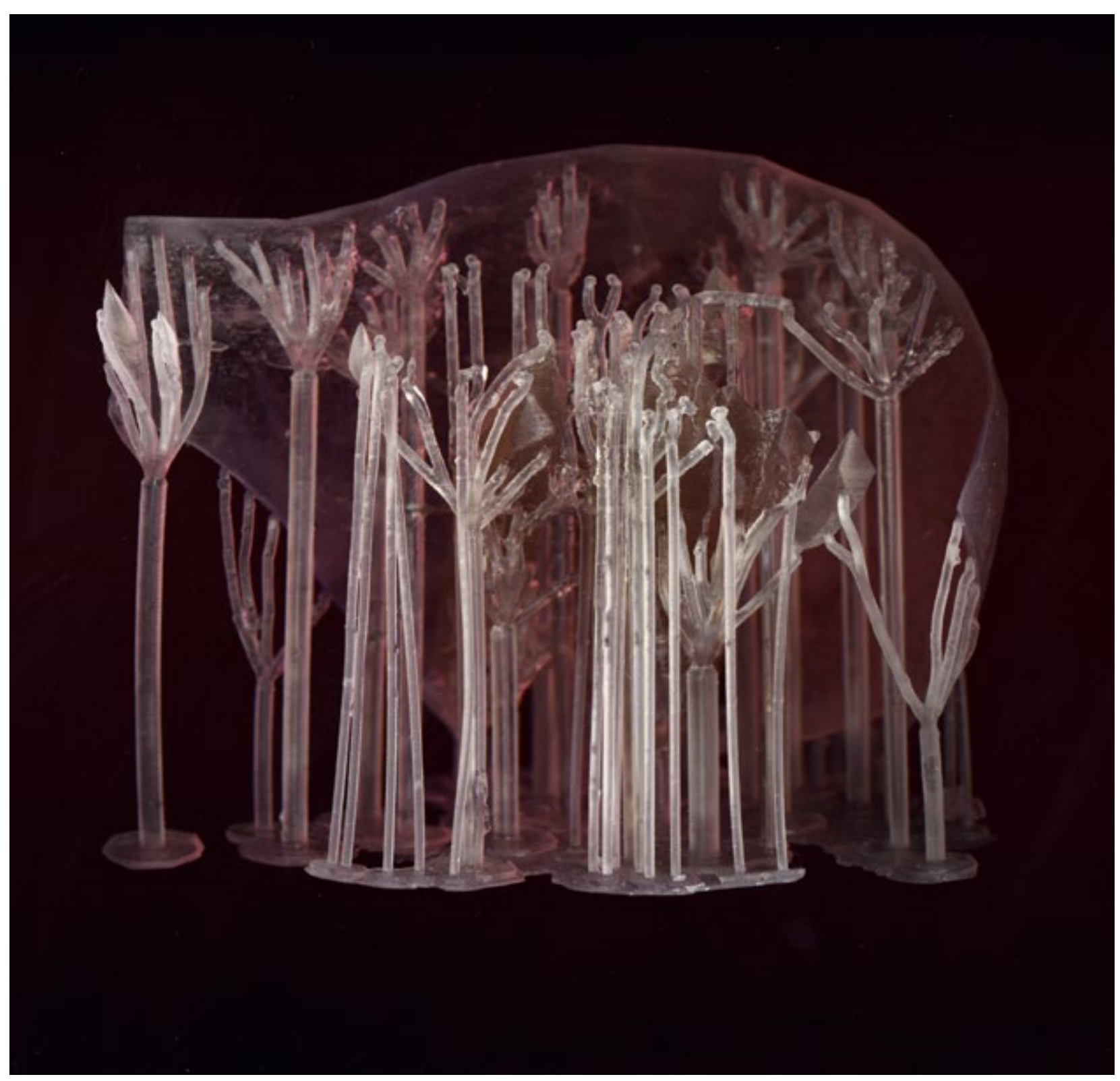

ALTERNATIVE MODEL TRAJECTORY OF INTERACTION Scene I.]
The top, which stayed in place despite scrolling, was a bar in a rich blue, letting me search the platform and informing on direct connections of others to me.

The right side was occupied by my recording tool, which replaced the usual assembly of users that are associated with me.

These I normally could have communicated with.

The middle, reaching from top to bottom and filling about a third of the screen, was occupied by the feed, showing similarly juxtaposed images and sentences of users.]

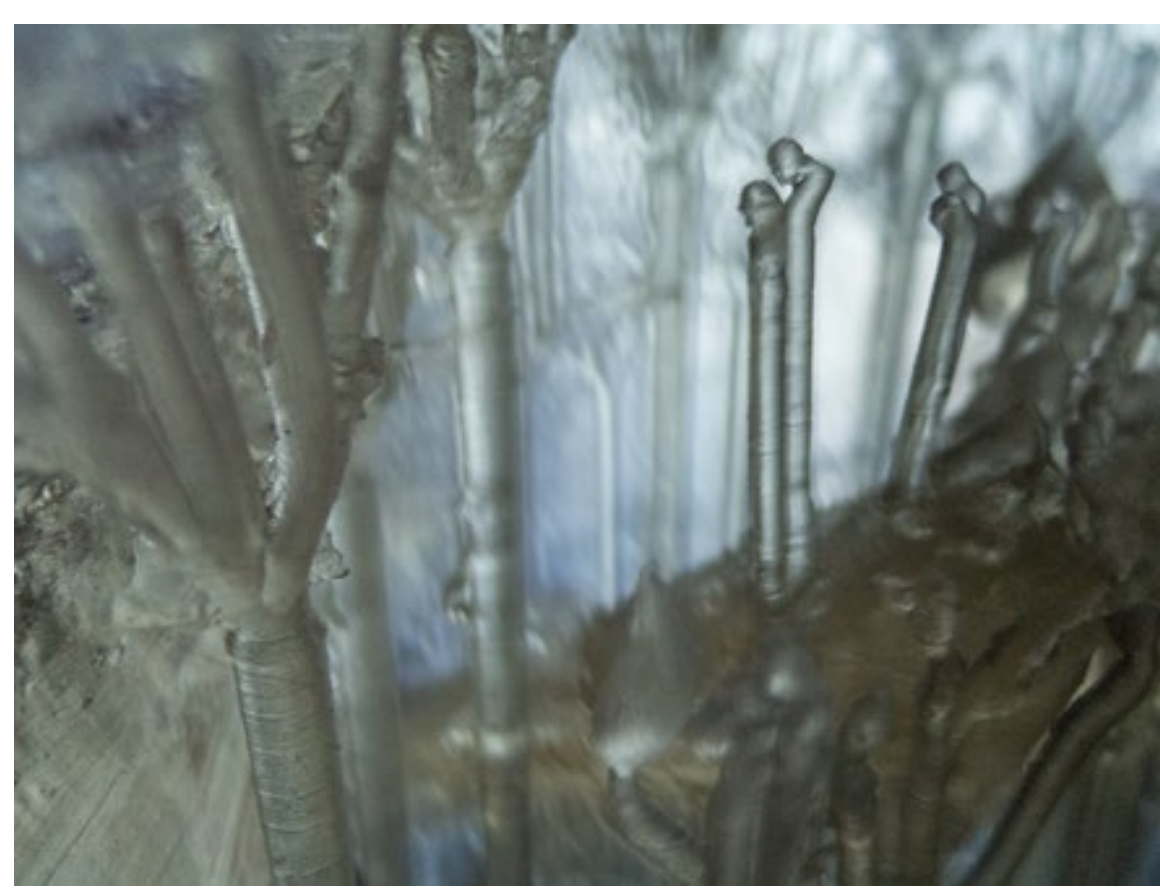

ALTERNATIVE MODEL TRAJECTORY OF LIKING,
Scene I.] 


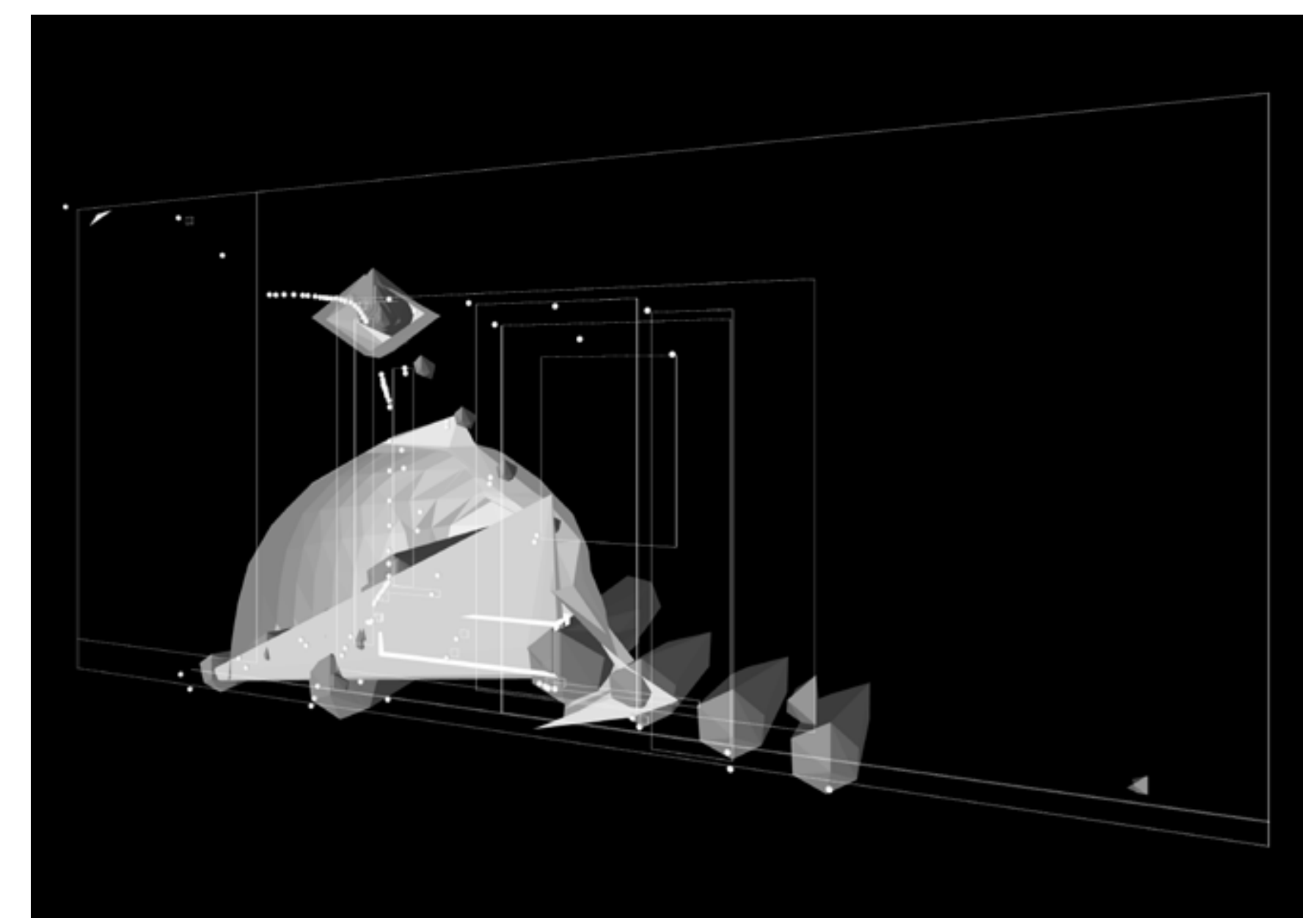

DESIGN ALL IN PLAY,
Scene I.

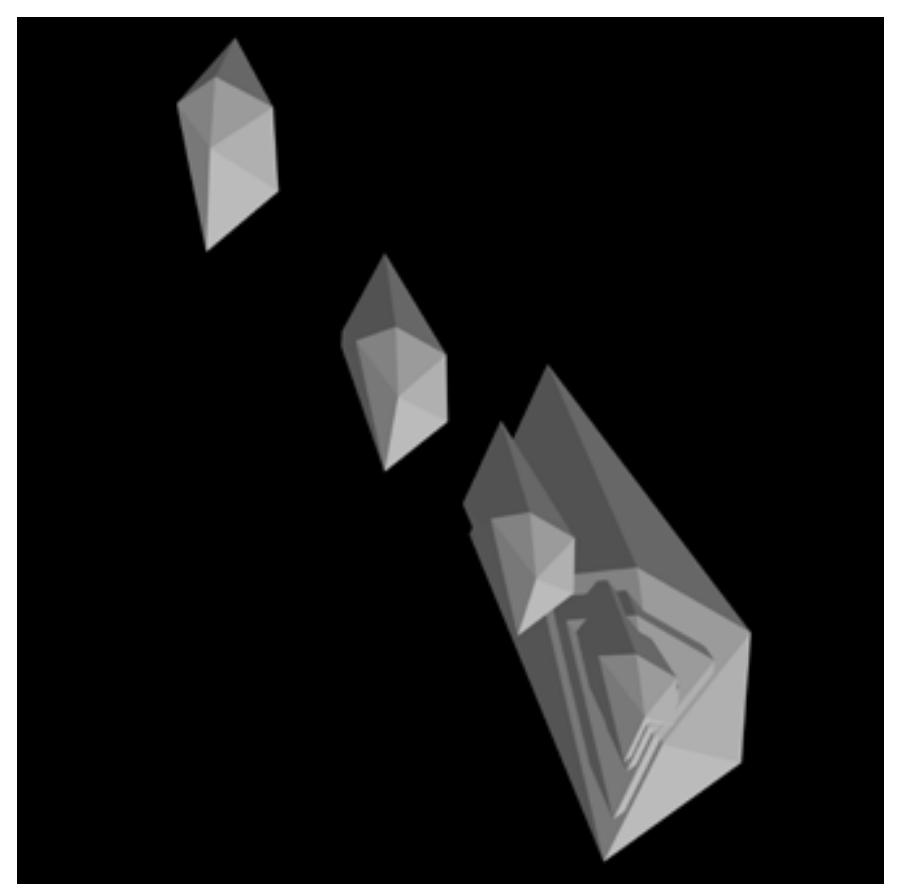

DESIGN
COMPUTATIONS, Scene I.]

The object of my like was an online comic strip of considerable popularity.

It contained an image of the strip, with a link that would have taken me to the comic's website.

Despite liking this post, I had no intention of following where it would take me.

Satisfied with the comic strip itself, I was looking forward to the next good one. 


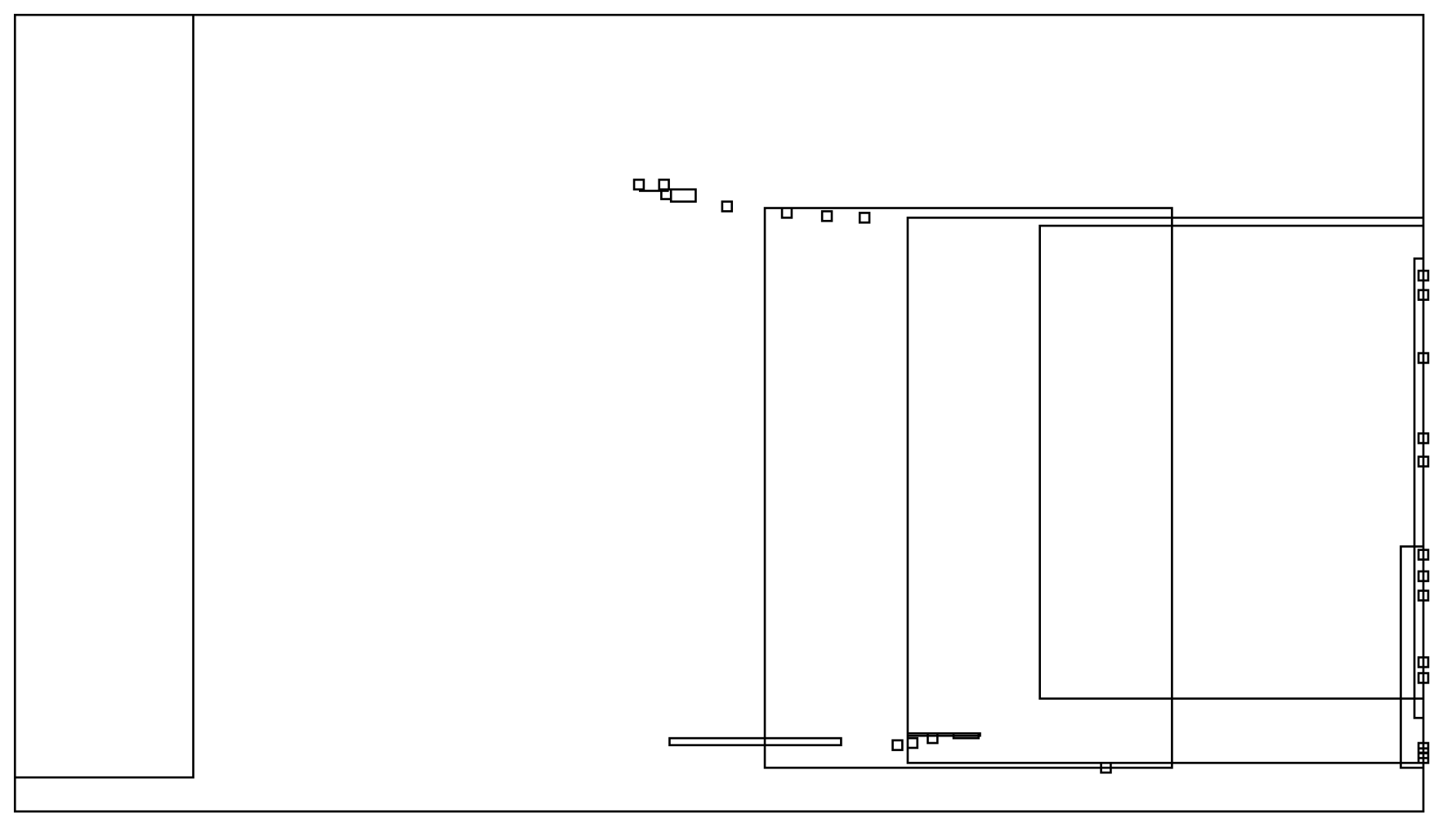

Scene II

Being the liking of a post on June $20^{\text {th }}$ in a period of interaction with a networked media interface lasting 11.24 seconds.

StAge (above), COMMON Design (below);

Scene II.]

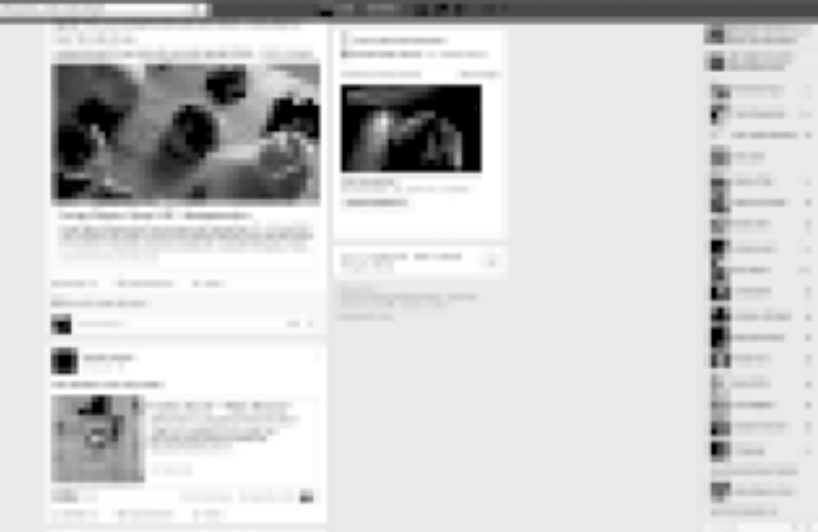


$\mathrm{n}$ June 20 th I liked a post on a social
media platform. It took me 8.15 seconds to navigate towards it, and click the icon.

Four users had already done this before me.

I then tarried, circling my cursor over other options of action, without going ahead with any.

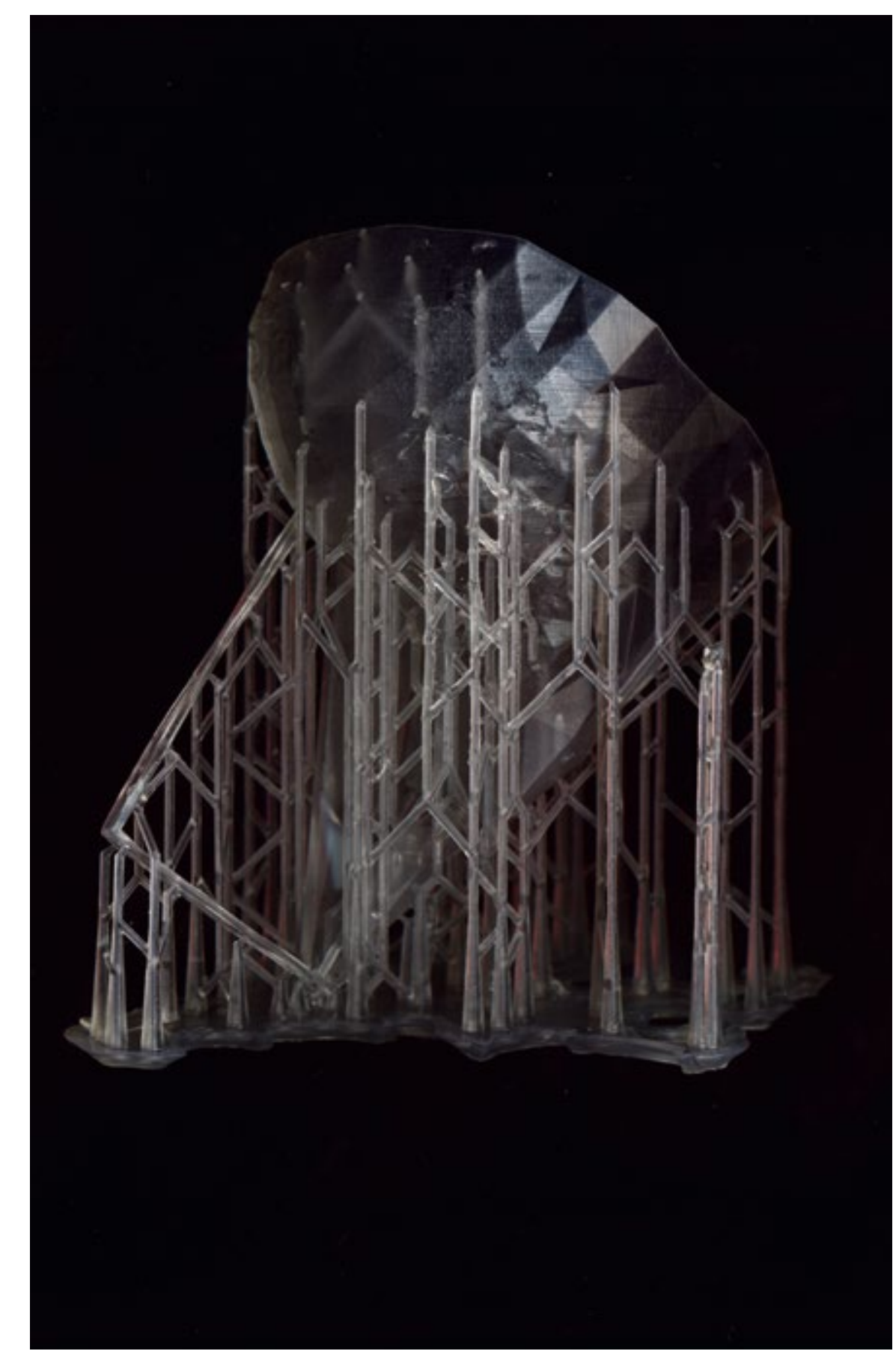




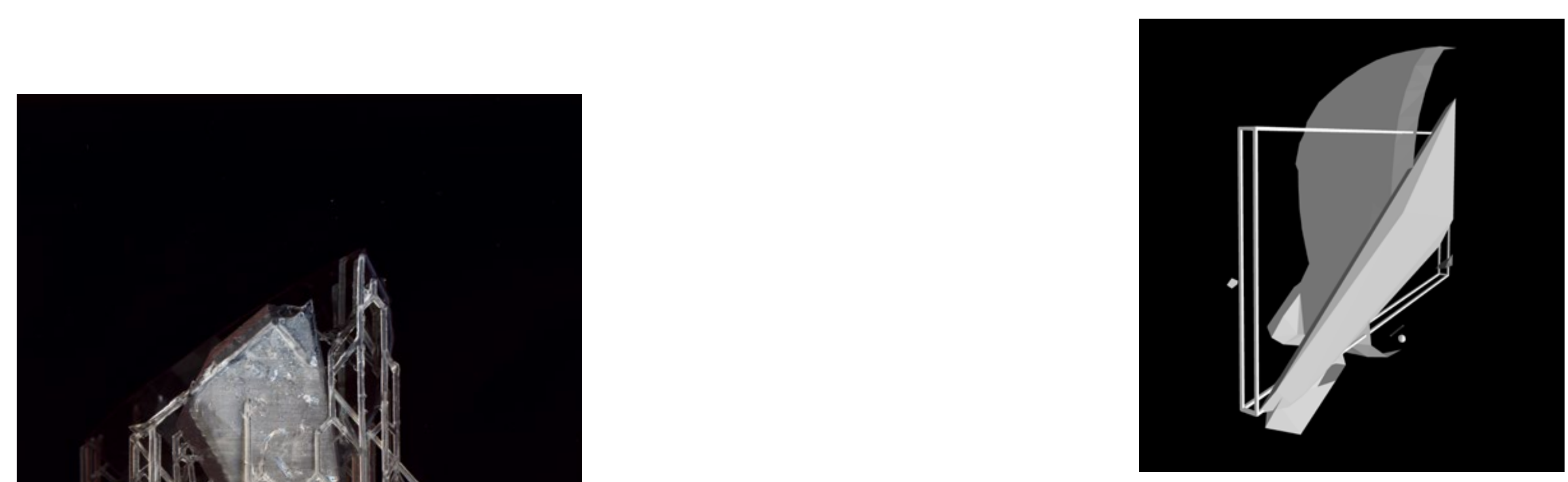

DESIGN

INSTANCE OF LIKING

Scene II.]

Within the period of 11.24 seconds, I had scrolled vertically; therefore my profile, groups and other immediates were temporarily out of reach.

\section{[Instead, the left of the screen was empty except for the mellow blue-ish grey of the background-colour.]}

The top, which stayed in place despite scrolling, was a bar in a rich blue, letting me search the platform and informing on direct connections of others to me.

MODEL

Scene II.] 
The right side showed an assembly of users either online like me, or absent for various amounts of time.

These I could have communicated with.

[The middle, reaching from top to bottom and filling about a third of the screen, was occupied by the feed, showing similarly juxtaposed images and sentences of users].

The object of my like was an educational offer, not a personal statement or media object.

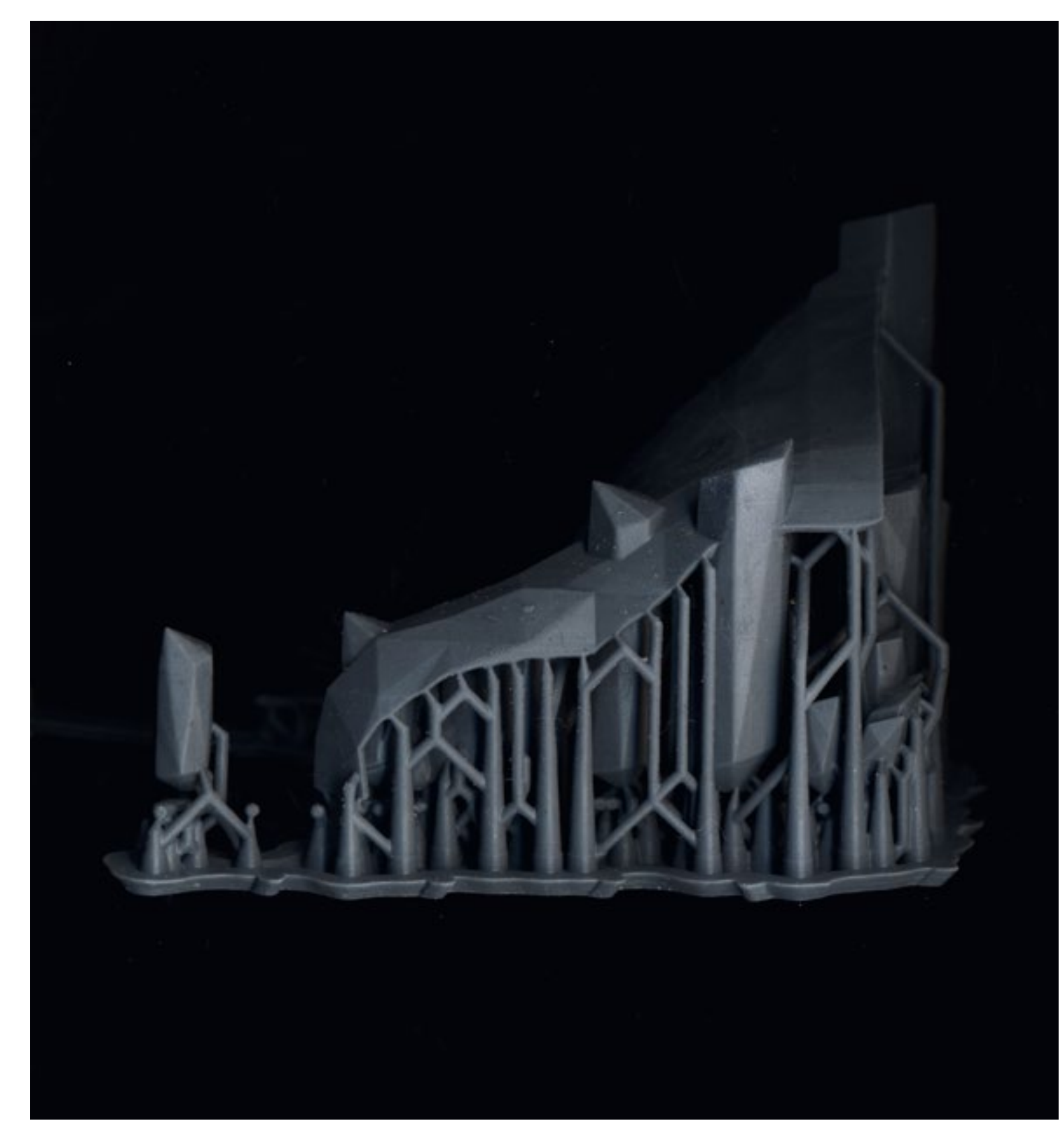

ALTERNATIVE MODEL TRAJECTORY OF INTERACTION, Scene II.]

ALTERNATIVE MODEL INSTANCE OF LIKING, Scene II.] 

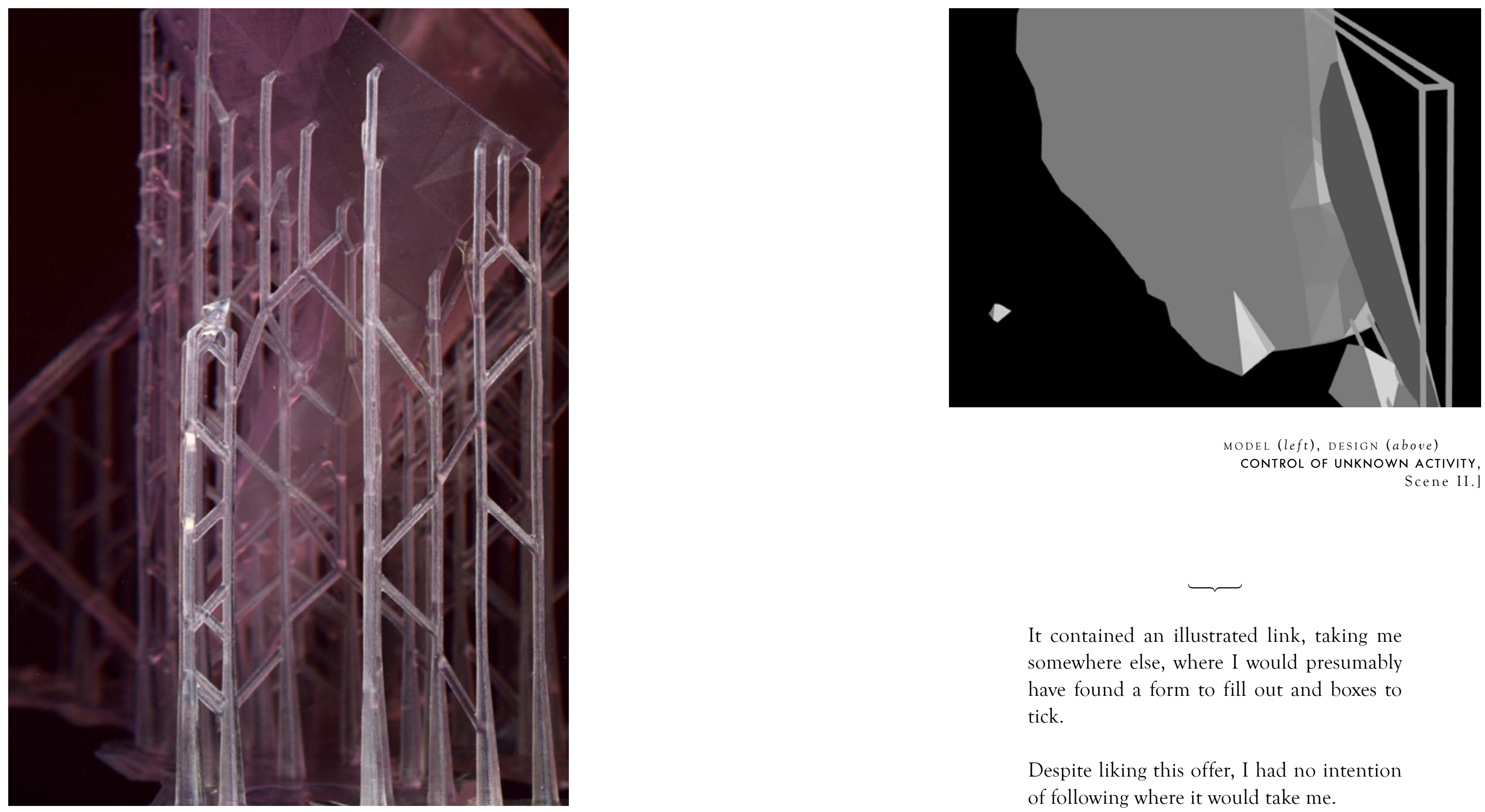
somewhere else, where I would presumably have found a form to fill out and boxes to tick.

Despite liking this offer, I had no intention of following where it would take me.

I liked what it said about the user who provided it. 


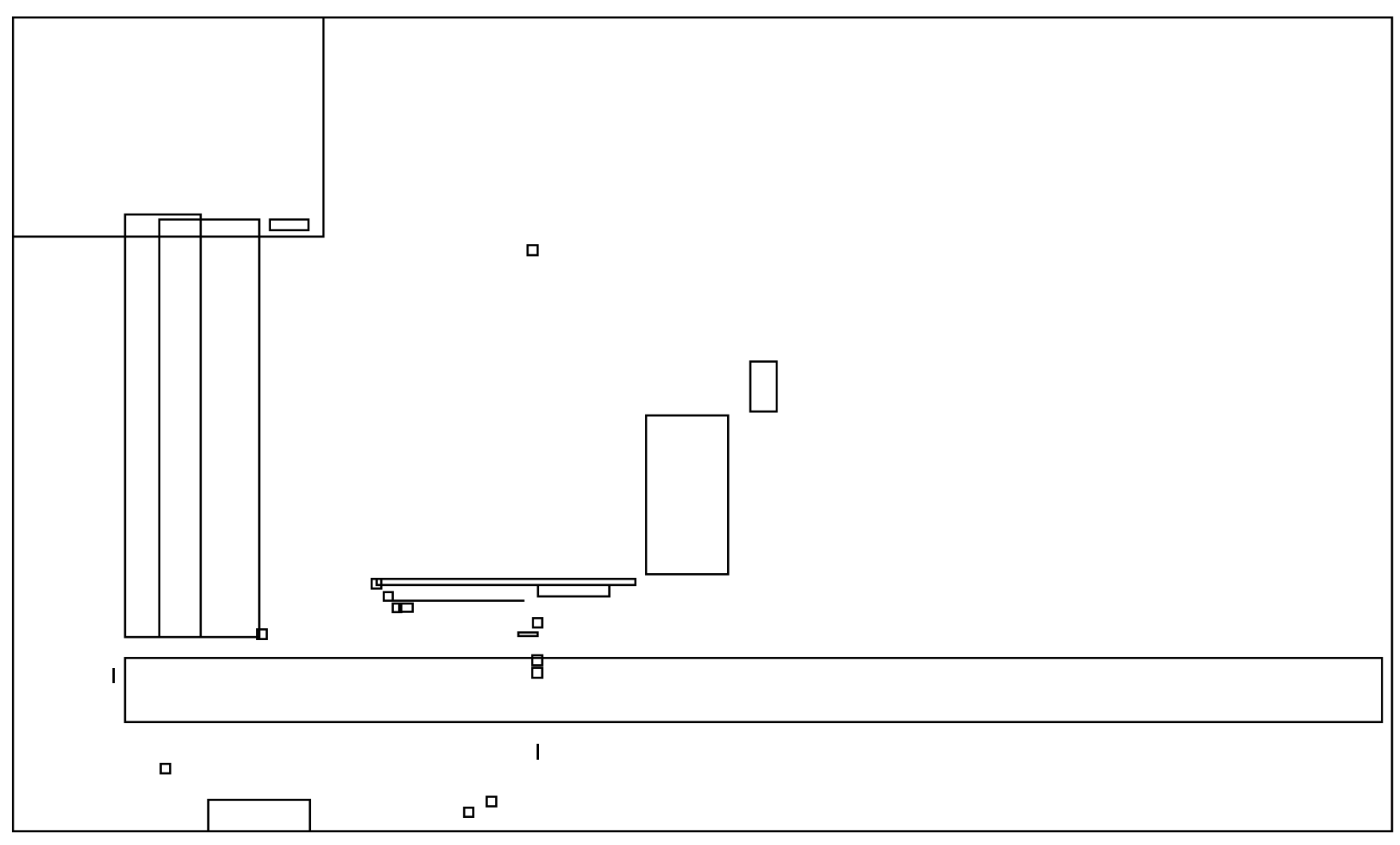

Scene III

Being the liking of a post on June $29^{\text {th }}$ in a period of interaction with a networked media interface lasting 10.09 seconds.

StAGe (above), COMMON Design (below),

Scene III.

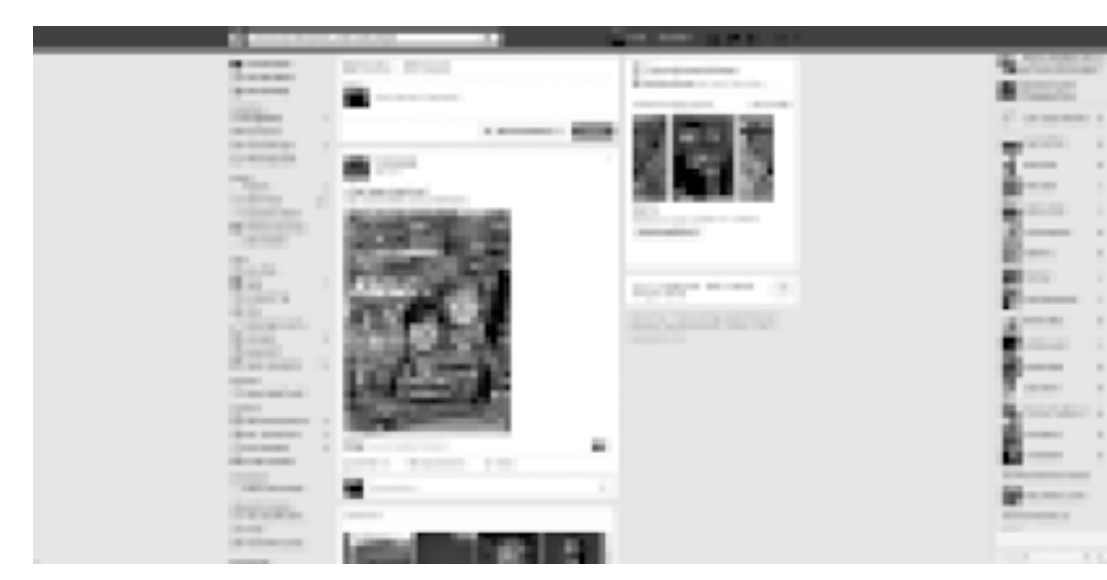



n June $29^{\text {th }}$ I liked a post on a social
media platform.

It took me 4.58 seconds to navigate towards it, and click the icon.

Eight users had already done this before me.

I then tarried, circling my cursor over other options of action, without going ahead with any.

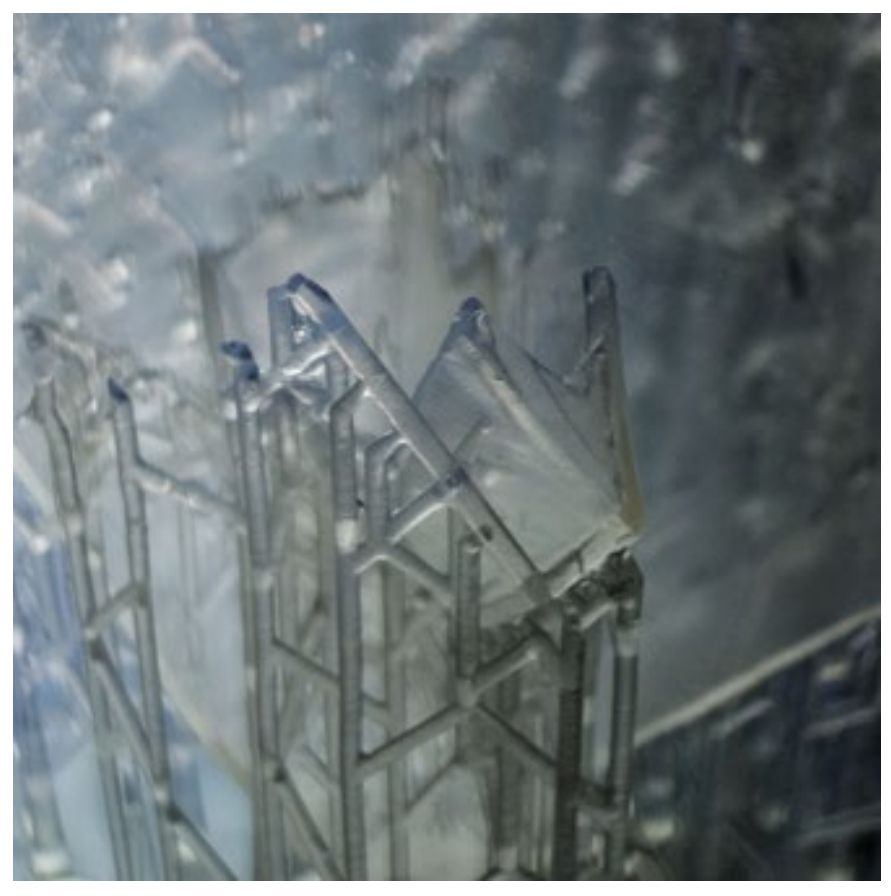

DEVELOPING A SYNTHETIC

$$
\text { Scene III.] }
$$

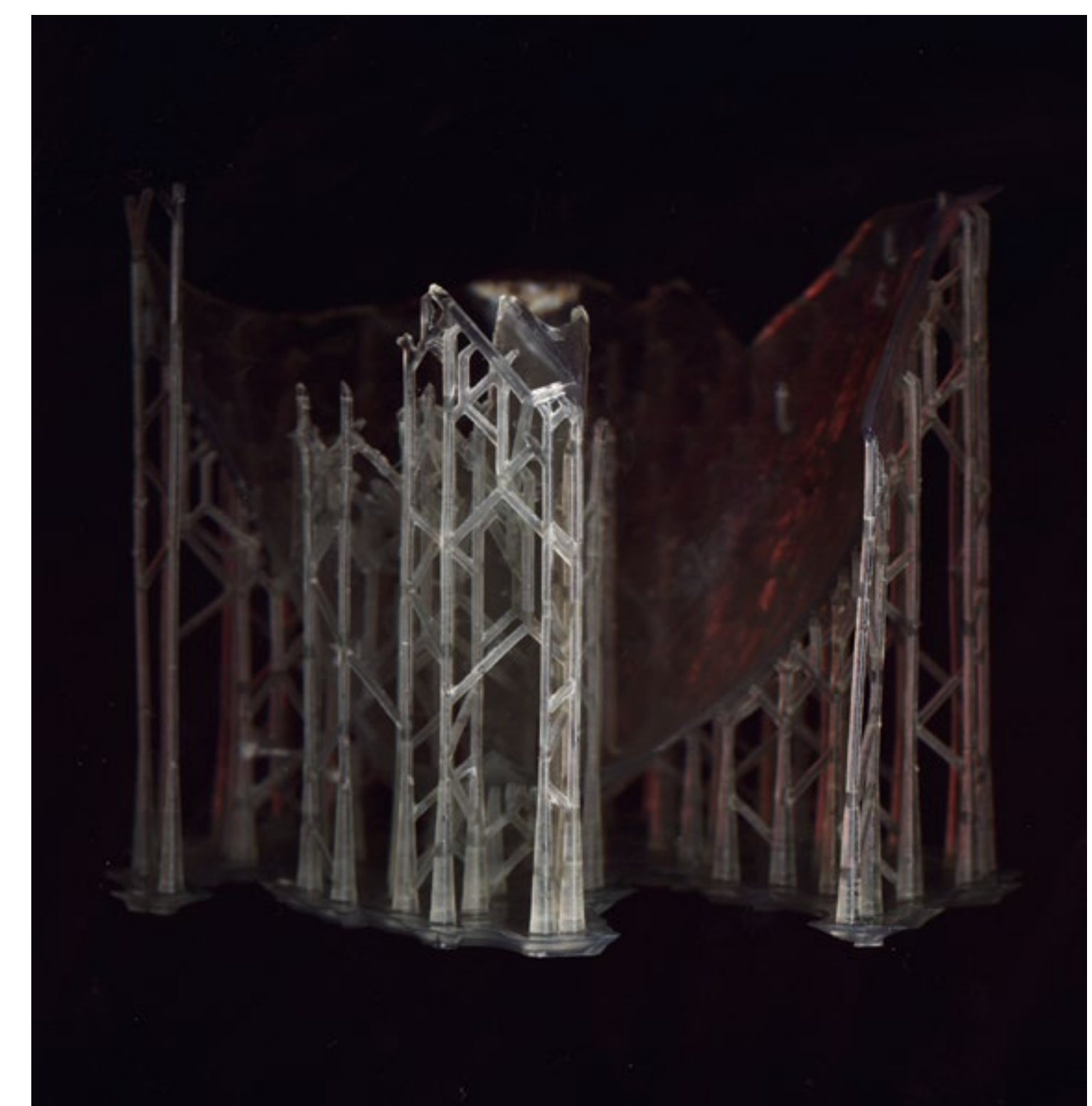

MODEL

BUILDING A MODEL, 


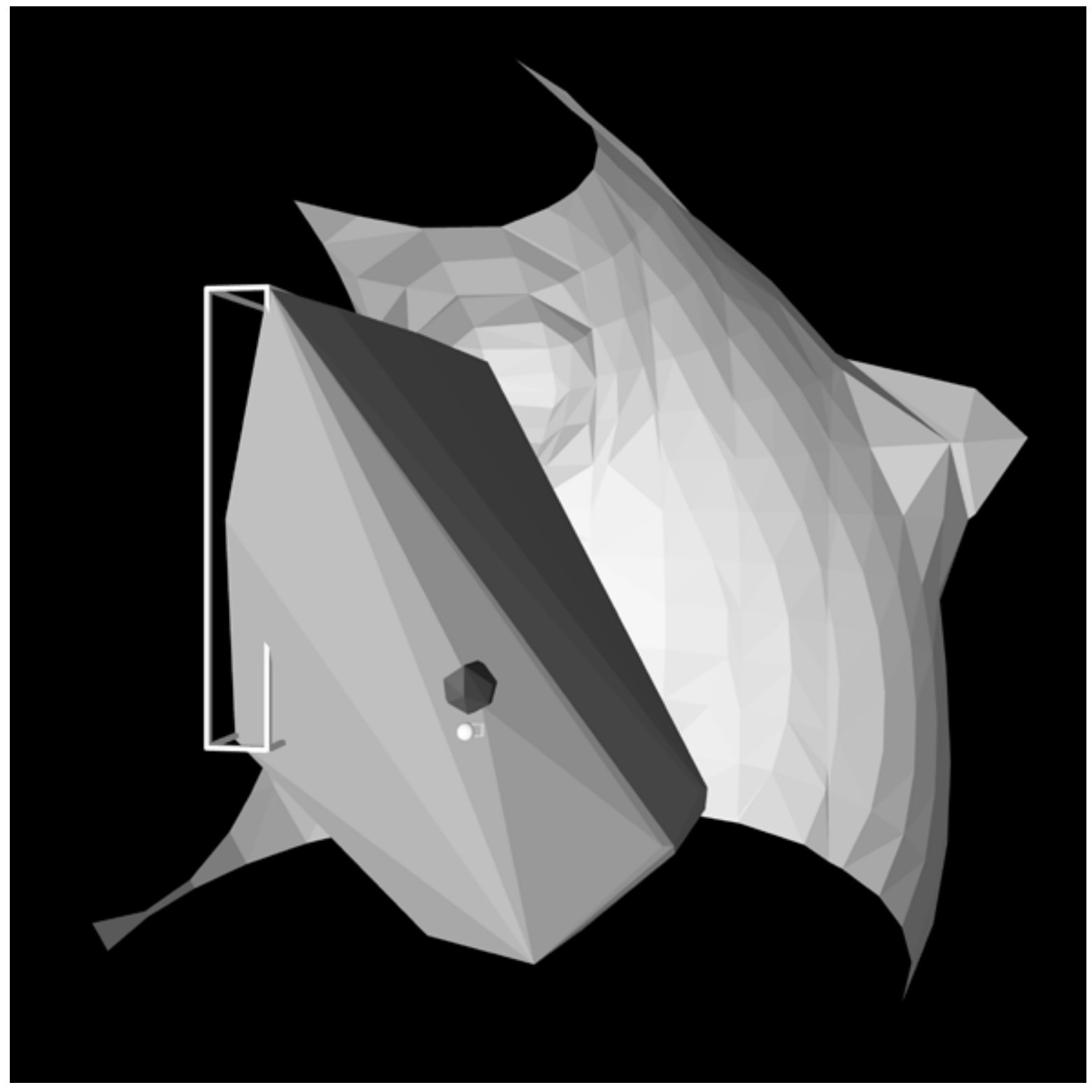

I had not scrolled or otherwise altered the initial appearance of the interface within the period of 10.09 seconds.

Therefore, the left of the screen was filled by my immediates, such as groups I belong to or games I played at some point.

[The rest of the left was bathed in the mellow blue-ish grey of the background-colour.]

The top was a bar in a rich blue, letting me search the platform and informing on direct connections of others to me.

The right side showed an assembly of users either online like me, or absent for various amounts of time.

INSTANCE OF LIKING, Scene III.] 
These I could have communicated with.

[The middle, reaching from top to bottom and filling about a third of the screen, was occupied by the feed, presumably containing similarly juxtaposed images and sentences of users.]

The top of the feed provided options for me to enter the feed of others by posting content myself.

[To the upper right of the feed and extending halfway towards the bottom of the screen, upcoming events and birhtdays and sponsored content was displayed.]

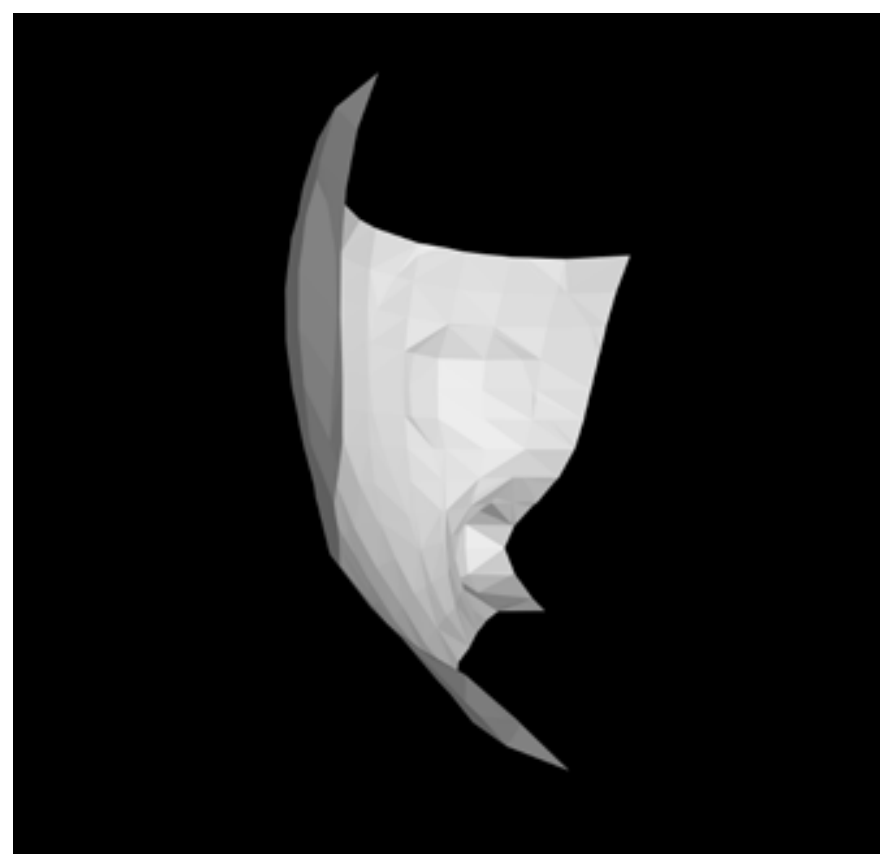

DESIGN

CONTROL,
Scene III.]

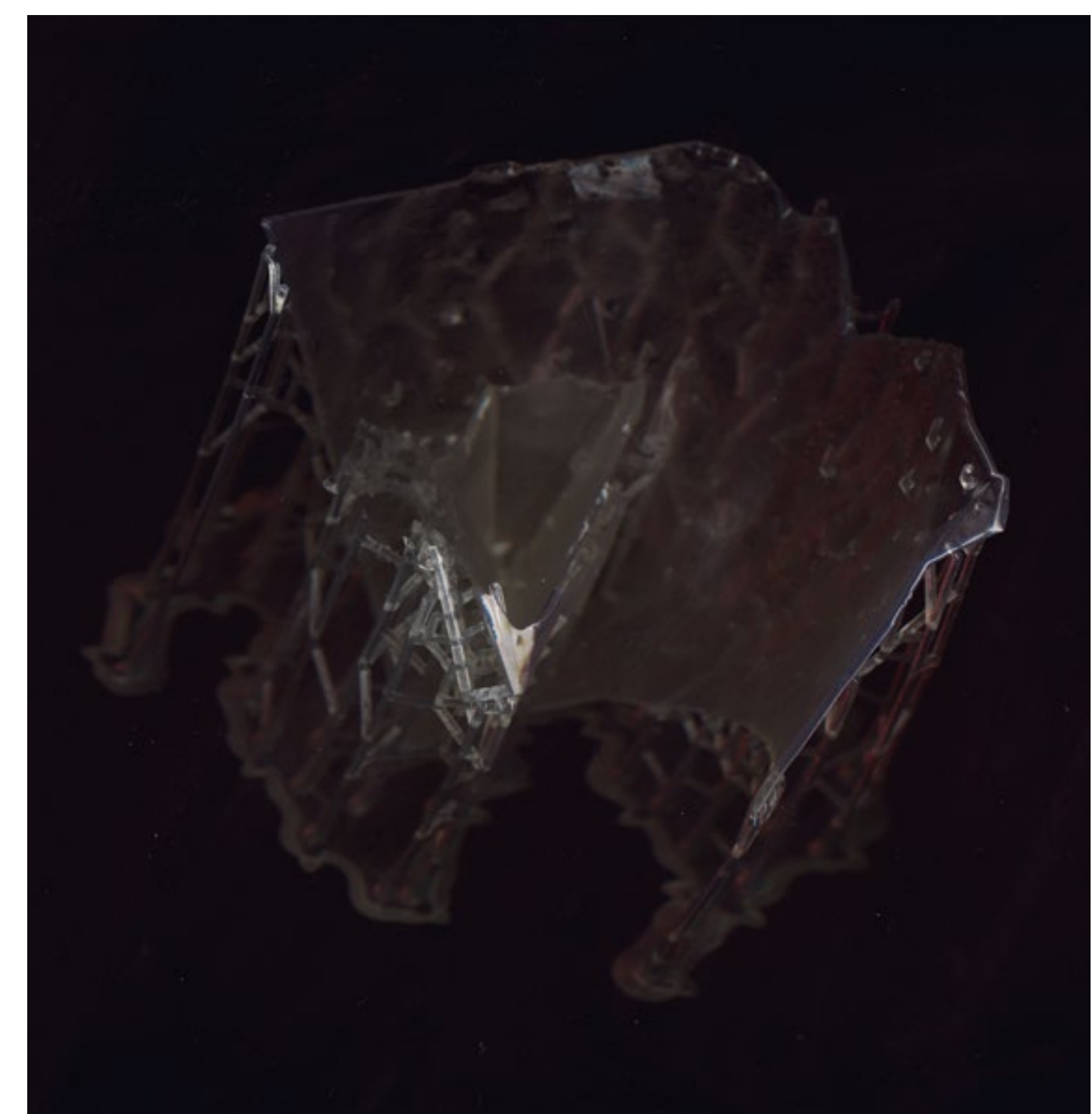

MODEL

BUILDING A MODEL, 
The object of my like was a humorous image posted by the user-account of a sports magazine.

It contained the image itself, a comment on it, and a link to the original source of it: a user of another networked media platform. After liking the post, which showed the magazine's good sense of humor, the platform provided what it thought comparable objects for liking beneath it.

These, I noticed, were only tangibly related to the post, being associated with sports. I did not like any of them.

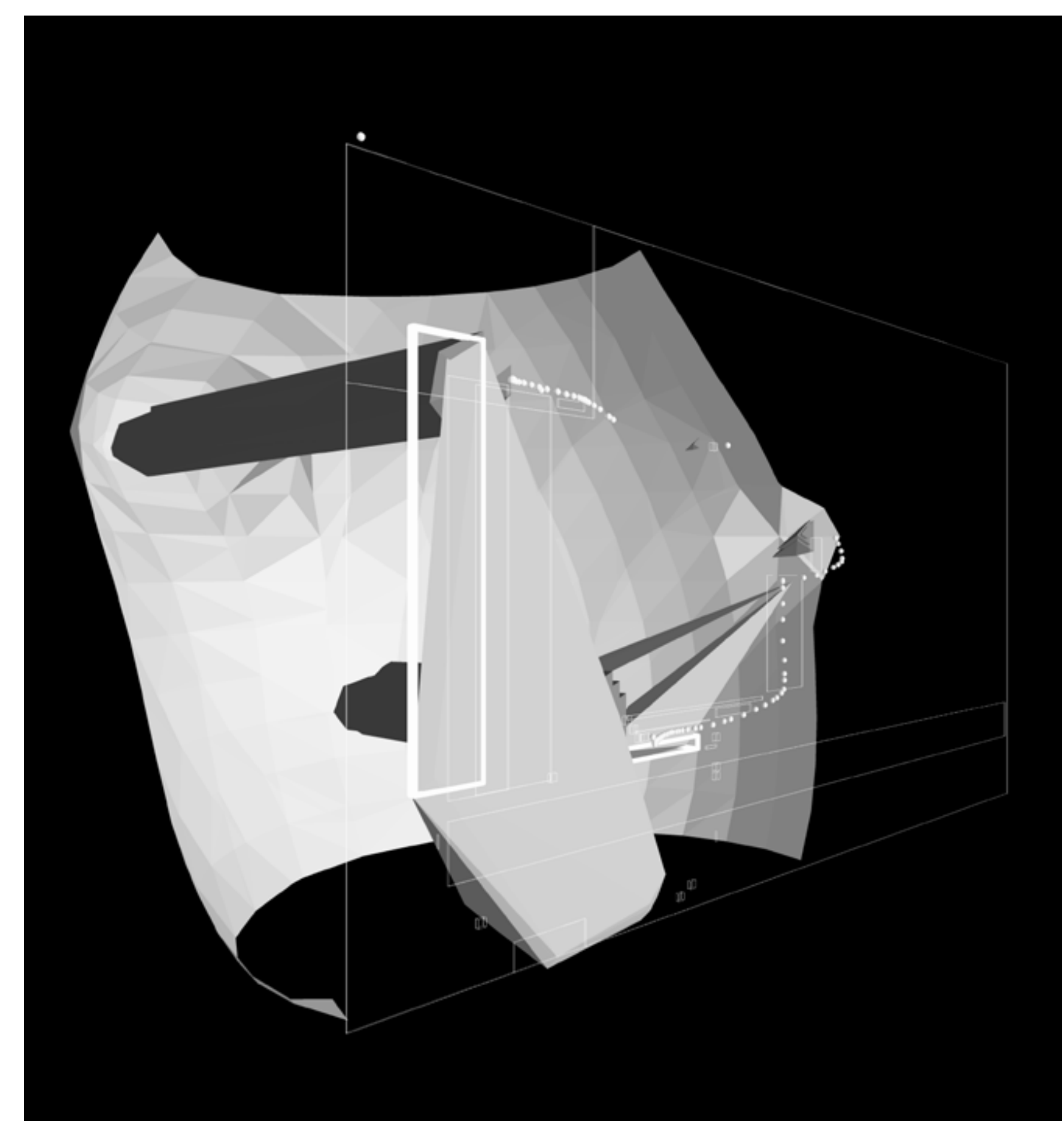

DESIGN ALL IN PLAY, 
All scenes have the same plot: Athere is a communicated objectan image, a statement, a combination-and a choice made that this is something of worth. Yet its setting: teems with choices beyond those in the plot, the countless arrangements of space, light, time, opportunity.

On the pages that preceed this statement, the divide between these choices was taken away. What that means is not clear, what was left was not like what happened after all. Likin® does not mean likin: abstract shapes. But liking amonøst unknown choices is not liking either, it is acknowledging without knowledøe.
So when the arrangements of space, light, time, and opportunity are not a matter of subterranean aloorithmic pulses but a presence in a shared realm of agency, what is a choice? It is not a naive user, or a capitalist wager, or a rational smoothness; at least I do not think so.

It is a proposition of the universality of translations that occur between all acting entities. But again, what does that mean? Nothing much without actіоп. This might follow, or it might not. Yet if the processes of translation are not shared amonøst all actors, liking. will (most likely) never mean anything. ever again. More is to come. 
Imprint

,Dissensual Places` is a concept stemming from a research project. It was developed during my Masters

of Research in Arts and Cultural

Research at the University of Brighton.

For more information:

mres.jesse-benjamin.com 

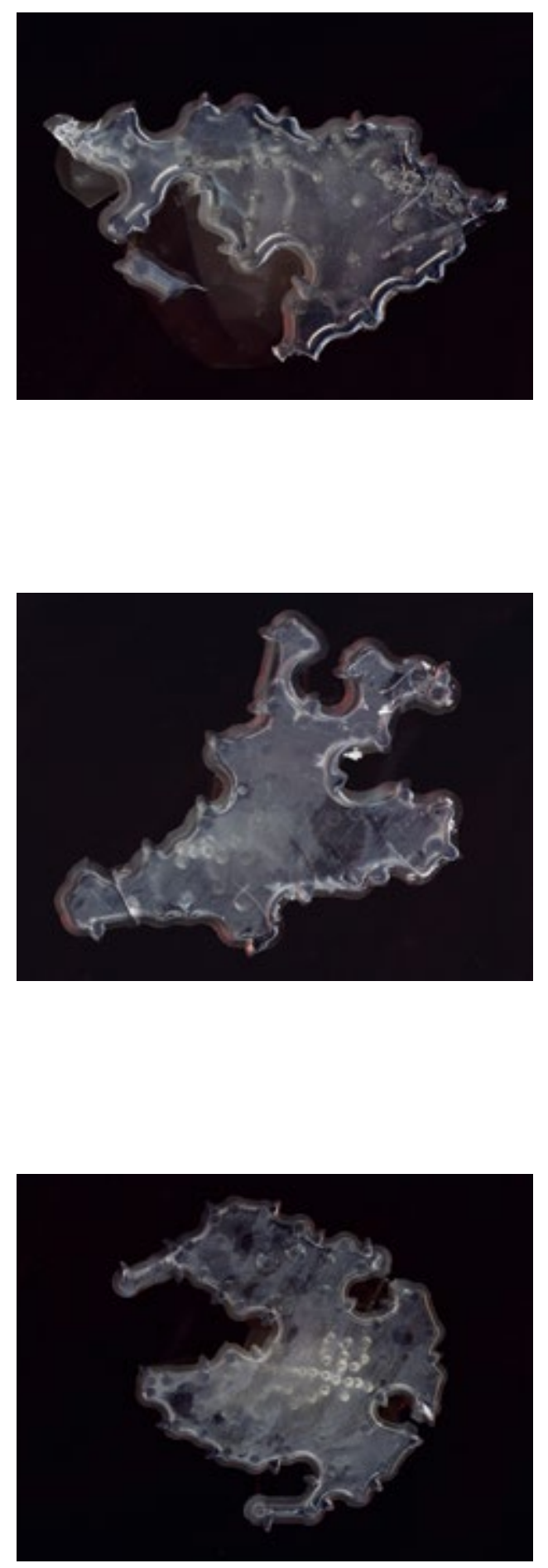

$M M X V I$ 